\title{
Psychological factors as risk factors for poor hip function after total hip arthroplasty
}

\author{
This article was published in the following Dove Press journal: \\ Therapeutics and Clinical Risk Management \\ 21 February 2017 \\ Number of times this article has been viewed
}

\author{
Achim Benditz' \\ Petra Jansen ${ }^{2}$ \\ Jan Schaible' \\ Christina Roll' \\ Joachim Grifka' \\ Jürgen Götz' \\ 'Department of Orthopedics, \\ University Medical Center \\ Regensburg, Asklepios Klinikum \\ Bad Abbach, Bad Abbach, ${ }^{2}$ Department \\ of Sport Science, University of \\ Regensburg, Regensburg, Germany
}

\begin{abstract}
Recovery after total hip arthroplasty (THA) is influenced by several psychological aspects, such as depression, anxiety, resilience, and personality traits. We hypothesized that preoperative depression impedes early functional outcome after THA (primary outcome measure). Additional objectives were perioperative changes in the psychological status and their influence on perioperative outcome. This observational study analyzed depression, anxiety, resilience, and personality traits in 50 patients after primary unilateral THA. Hip functionality was measured by means of the Harris Hip Score. Depression, state anxiety, and resilience were evaluated preoperatively as well as 1 and 5 weeks postoperatively. Trait anxiety and personality traits were measured once preoperatively. Patients with low depression and anxiety levels had significantly better outcomes with respect to early hip functionality. Resilience and personality traits did not relate to hip functionality. Depression and state anxiety levels significantly decreased within the 5-week stay in the acute and rehabilitation clinic, whereas resilience remained at the same level. Our study suggests that low depression and anxiety levels are positively related to early functionality after THA. Therefore, perioperative measurements of these factors seem to be useful to provide the best support for patients with risk factors.
\end{abstract}

Keywords: total hip arthroplasty, psychological factors, depression, state anxiety, trait anxiety, resilience, personality traits

\section{Introduction}

Osteoarthritis is a degenerative joint disease that may affect every joint of the body. Hips and knees, in particular, are often affected, and hip osteoarthritis is one of the most common types of osteoarthritis. ${ }^{1}$ If conservative treatment options are exhausted, joint replacement surgery is a widely accepted, effective treatment option for end-stage osteoarthritis. ${ }^{2}$ Although joint replacement surgery is the most successful orthopedic surgical intervention, not every patient is completely satisfied after surgery. ${ }^{3-6}$ Therefore, over the past few years, interest has been focused on the influence of psychological factors on outcome after total knee arthroplasty (TKA) and total hip arthroplasty (THA). Vissers et $\mathrm{al}^{7}$ conducted a systematic review of what psychological factors influence the outcome after THA or TKA and to what extent. They found that pain catastrophizing and impaired mental health before TKA were associated with lower scores for function and higher scores for postoperative pain. Moreover, their results indicated that preoperative depression does not influence postoperative functioning. Another finding of their study was that only a few studies on psychological factors after THA are available so far, and that these studies have yielded limited or conflicting results. ${ }^{6,8-13}$

Our study concentrated on the influence of psychological factors on the outcome after THA. We focused on psychological factors such as major depression, state and
Correspondence: Achim Benditz Department of Orthopedics, Orthopädische Klinik für die Universität Regensburg, Asklepios Klinikum Bad Abbach, Kaiser-Karl-V-Allee 3, 93077 Bad Abbach, Germany Tel +49 1728330955

Email achim.benditz@ukr.de 
trait anxiety, resilience, and personality traits that play an important role in today's medicine according to the World Health Organization's (WHO) Global Burden of Disease Study. ${ }^{14}$ The prevalence of these factors is likely to increase in the coming years. A large study, including more than 200,000 participants in 60 countries, investigated combinations of diseases. Depression was found to have the most negative influence on health in combination with other diseases, such as angina, arthritis, asthma, or diabetes. ${ }^{15}$ Several studies have evaluated psychological aspects in orthopedics, eg, the effect of depression on the occurrence of femoral neck fractures and distal radius fractures. ${ }^{16-18}$ A research group from Italy has reported about the positive influence of psychological support of patients undergoing THA or TKA. Regarding the hip arthroplasty group, patients receiving psychological support reached the physiotherapeutic objective 1.2 days earlier than patients without any such support. ${ }^{19}$ Other studies have dealt with the aspects of fear and pain in correlation with THA and TKA surgery ${ }^{20}$ or depression and anxiety as a predictor for complications. ${ }^{21}$ Buller et $\mathrm{al}^{22}$ have recently reported on the influence of psychiatric comorbidity (eg, depression, anxiety, dementia, and schizophrenia) on perioperative outcome after primary total hip and knee arthroplasty. Diagnosis of depression, dementia, and schizophrenia was associated with increased odds of adverse events. ${ }^{22}$ Overall, only a few studies have yet evaluated the influence of a variety of psychological dispositions on outcome after orthopedic surgery. According to the literature reports, we expected a relationship between depression and THA outcome measured with the Harris Hip Score (HHS), whereas a possible relationship between resilience, anxiety, and different personality traits remains to be investigated. Therefore, the main goal of our study was to investigate the relationship between depression, resilience, state and trait anxiety, and different personality traits and the healing process and early functional outcome measured by means of the HHS.

\section{Methods}

\section{Participants}

This prospective study included 50 patients who underwent total hip replacement in a center of excellence for arthroplasty. The inclusion period was 6 months, and inclusion criteria were 1) osteoarthritis of the hip; 2) exhausted conservative treatment; 3) age between 20 and 85 years; and 4) no previous hip surgery. The study was approved by the local Ethics Committee of the University of Regensburg (2009-09/136) and carried out in accordance with the approved guidelines of the Helsinki Declaration of 1975. Written informed consent was obtained from all study subjects. The study has been registered in the DRKS (Deutsches Register Klinischer Studien, German Clinical Trials Register, WHO register) with the DRKS00010536.

\section{Procedure}

The same group of senior surgeons conducted all surgical interventions as a consecutive series. Patients remained at the acute clinic for about 8 days followed by a 4-week stay at the rehabilitation center of the same hospital.

\section{Depression, anxiety, resilience, Freiburg Personality Inventory}

Thelevel of depression was measured by means of the "Allgemeine Depressionsskala" (general depression scale - long, ADS-L), which is the German version of the CES-D-Scale (Center for Epidemiological Studies Depression Scale). ${ }^{23-26}$

Anxiety was determined with the "State and Trait Anxiety Inventory" (STAI). ${ }^{27,28}$ Spielberger described state anxiety as "existing in a transitory emotional state", which varies in intensity and fluctuates over time, whereas trait anxiety refers to stable susceptibility or proneness to frequent experiences of state anxiety. ${ }^{27,28}$ STAI-X1 measures the state anxiety at the present time, which can be induced temporarily by different situations. The STAI-X2 measurement can be described as a relative stable disposition for anxiety that does not depend on a specific situation.

Resilience levels were measured with the "Resilience Scale" (RS-11) developed by Wagnild and Young. ${ }^{29}$ The authors equated "resilience" with emotional stamina, and this term has been used to describe people displaying courage and adaptability in the wake of life's misfortunes. Luthar et al ${ }^{30}$ used the term "resilience" for describing a person's capability to positively adapt to adverse conditions.

For the different personality traits, we used the Freiburg Personality Inventory - revised (FPI-R), which is a psychological test to assess personality. ${ }^{31}$ The application is focused, among others, on the area of rehabilitation. Twelve personality characteristics are assessed by means of 138 items of the FPI-R questionnaire: life satisfaction (LIF), social orientation (SOC), achievement orientation (ACH), inhibitedness (INH), impulsiveness (IMP), aggressiveness (AGG), strain (STR), somatic complaints (SOM), health concern (HEA), frankness (FRA), and two secondary factors (following Eysenck), namely, extraversion (EXT) and emotionality (neuroticism) (EMO).

\section{Function}

The HHS was used to assess the clinical health status relevant to THA outcome. ${ }^{32}$ This score includes a rating scale of 
100 points for the domains pain, function, activity, deformity, and motion. The HHS was first published in 1969 and has been established as a valid and reliable index to assess the results of hip replacement surgery. ${ }^{33-37}$

\section{Schedule}

Prior to surgery (T0), the psychological profile and hip status of each patient were established by evaluating the ADS-L, STAI-X1 and -X2, RS-11, FPI-R, and HHS. The ADS-L, STAI-X1, RS-11, and HHS were evaluated once again 1 week after surgery (T1), which was equivalent to the end of the stay at the acute clinic. The same procedure was conducted 5 weeks after THA (T2) in the rehabilitation center, in which all patients underwent the same rehabilitation program (Figure 1). At admission to hospital, all eligible patients were asked to participate. To determine the factors to be investigated and minimize the risks of exogenous influence in the home environment, we chose a 5-week follow-up period, which means that patients were seen after their stay in the acute clinic and rehabilitation center.

\section{Statistical analysis}

Statistical analysis consisted of both descriptive and inferential measures. Mean values and standard deviations (SDs) were calculated for continuous variables. After collecting the data, we divided the results of each psychological factor at T0 into two groups: Group 1 ( $\geq$ median) and Group 2 $(<$ median). The HHS was the dependent variable. The significance level was established at 0.05 . Furthermore, statistical significance for outcomes of interest was determined by means of multivariate analysis of variance (MANOVA). MANOVA was used because the HHS was registered at three different times, resulting in three different dependent variables. We decided to use the MANOVA, because a high correlation between the results of the HHS on the three measurement times could be assumed. For correlation analyses, Pearson product-moment correlation coefficient was used. All statistical analyses were done using Predictive Analytics Software 18.0 for Windows (SPSS Inc., Chicago, IL, USA).

\section{Results}

The analyzed cohort contained 27 women and 23 men. The mean age was 62.18 years $(\mathrm{SD}=11.48)$, body height was 5.54 feet $(\mathrm{SD}=0.27$ ), and body mass index 27.95 $(\mathrm{SD}=5.44)$ (Table 1). Twenty-seven patients received surgery at the right hip, and 23 patients at the left hip. Sixty-one patients were eligible for inclusion. Seven patients declined to participate, and in two patients, the

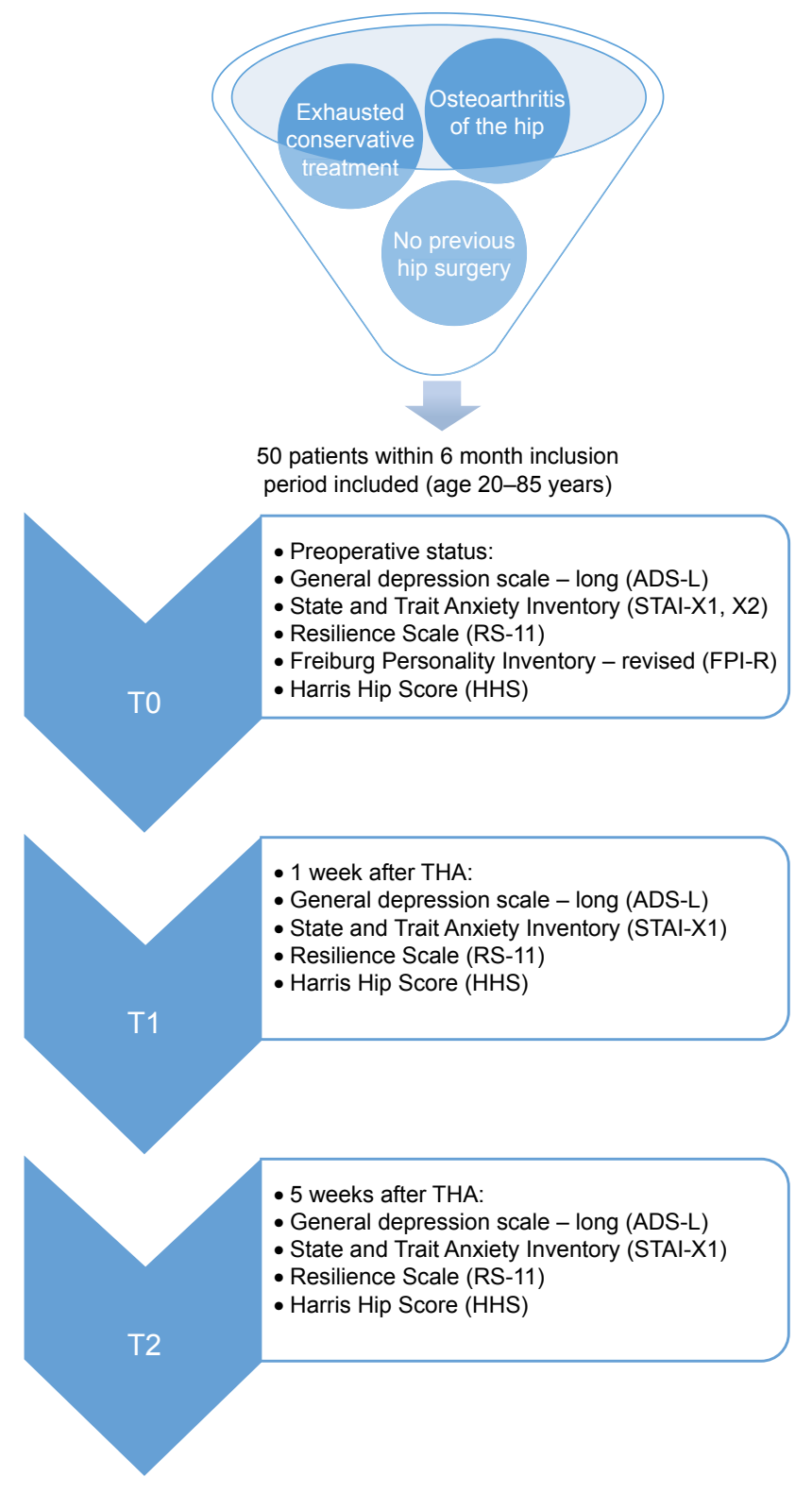

Figure I Flowchart of study design.

Note: ADS-L is the German version of the Center for Epidemiological Studies Depression Scale.

Abbreviations: T0, prior to surgery; TI, I week after surgery; T2, 5 weeks after surgery.

operation had to be canceled because of increased inflammation parameters. Two patients withdrew their consent without any reason.

\section{Change of psychological factors (descriptive data)}

The ADS-L (the general depression scale) increased from $16.8 \pm 8.8$ (T0) to $17.6 \pm 9.3$ (T1) and then decreased to $11.9 \pm 6.2$ (T2) (Table 2). State anxiety (X1) started at $44.1 \pm 12.3$, decreased continuously to $38.9 \pm 11.0$, and finally dropped to $35.1 \pm 10.2$. 
Table I Demographic data of the included patients

\begin{tabular}{lll}
\hline Demographic data & $\mathbf{N}, \mathbf{n}(\%)$, mean \pm SD & Range \\
\hline Participants & $\mathrm{N}=50$ & \\
Sex & & \\
$\quad$ Male & $23(46 \%)$ & \\
Female & $27(54 \%)$ & \\
Age & $62.18 \pm 11.48$ & $42-85$ \\
BMI & $27.95 \pm 5.44$ & $21.34-37.23$ \\
\hline
\end{tabular}

Abbreviations: BMI, body mass index; SD, standard deviation.

Trait anxiety was expected to be a continuous parameter and was therefore assessed just once, yielding a value of 38.7 \pm 9.9 . RS-11 results confirmed the expectation of resilience to also be a continuous parameter. The mean value was constant at 59.9 $\pm 11.0,59.3 \pm 11.1$, and 59.7 \pm 11.0 . The results of FPI-R are shown in Table 3.

The HHS indicated improved early outcome after surgery. The preoperative result was $49.6 \pm 19.8$, the result at T1 was $60.0 \pm 13.9$ and $73.3 \pm 8.8$ at $\mathrm{T} 2$.

\section{Independent psychological factors for hip functionality Depression score and HHS}

The results showed that the degree of depression is related to the HHS outcome at every point in time $(\mathrm{T} 0: F(1.48)=6.146$, $P=0.017, \eta_{2}=0.114 ; \mathrm{T} 1: F(1.48)=6.570, P=0.014, \eta_{2}=0.120$;

Table 2 Descriptive statistics at T0, TI, and T2, (N=50)

\begin{tabular}{cclll}
\hline $\begin{array}{l}\text { Scalel } \\
\text { inventory }\end{array}$ & Mean & $\begin{array}{l}\text { Standard } \\
\text { deviation }\end{array}$ & Minimum & Maximum \\
\hline $\begin{array}{c}\text { STAI-XI } \\
\text { T0 }\end{array}$ & 44.06 & 12.325 & 21 & 68 \\
TI & 38.88 & 10.963 & 20 & 59 \\
T2 & 35.14 & 10.162 & 20 & 61 \\
ADS-L & & & & \\
T0 & 16.80 & 8.753 & 0 & 37 \\
TI & 17.58 & 9.335 & 0 & 39 \\
T2 & 11.90 & 7.731 & 0 & 31 \\
RS-II & & & & \\
T0 & 59.86 & 11.014 & 36 & 77 \\
TI & 59.26 & 11.069 & 22 & 77 \\
T2 & 59.74 & 10.980 & 34 & 77 \\
HHS & & & & \\
T0 & 49.66 & 19.848 & 17 & 92 \\
TI & 60.00 & 13.974 & 23 & 85 \\
T2 & 73.28 & 8.825 & 46 & 86 \\
\hline
\end{tabular}

Notes: ADS-L is the German version of the Center for Epidemiological Studies Depression Scale. STAI-XI measures the state anxiety at the present time, which can be induced temporarily by different situations.

Abbreviations: T0, prior to surgery; TI, I week after surgery; T2, 5 weeks after surgery; STAI, State and Trait Anxiety Inventory; ADS-L, Depression scale - long; RS-I I, Resilience Scale; HHS, Harris Hip Score.
Table 3 Results of the FPI-R $(\mathrm{N}=50)$

\begin{tabular}{lllll}
\hline FPI-R & $\begin{array}{l}\text { Mean } \\
\text { (points) }\end{array}$ & $\begin{array}{l}\text { SD } \\
\text { (points) }\end{array}$ & $\begin{array}{l}\text { Minimum } \\
\text { (points) }\end{array}$ & $\begin{array}{l}\text { Maximum } \\
\text { (points) }\end{array}$ \\
\hline Life satisfaction (LIF) & 8.04 & 2.955 & $\mathrm{I}$ & 12 \\
Social orientation (SOC) & 7.66 & 2.153 & 4 & 12 \\
$\begin{array}{l}\text { Achievement } \\
\text { orientation (ACH) }\end{array}$ & 6.70 & 2.243 & 2 & 11 \\
Inhibitedness (INH) & 5.14 & 2.540 & $\mathrm{I}$ & $\mathrm{II}$ \\
Impulsiveness (IMP) & 4.62 & 2.755 & 0 & 10 \\
Aggressiveness (AGG) & 2.32 & 1.708 & 0 & 8 \\
Strain (STR) & 4.74 & $3.28 \mathrm{I}$ & 0 & 12 \\
Somatic complaints & 3.10 & 2.501 & 0 & 10 \\
(SOM) & & & & \\
Health concern (HEA) & 7.24 & 2.237 & 3 & 12 \\
Frankness (FRA) & 4.28 & 2.807 & 0 & 11 \\
Extraversion (EXT) & 5.70 & 3.228 & 0 & 12 \\
$\begin{array}{l}\text { Emotionality } \\
\text { (neuroticism) (EMO) }\end{array}$ & 5.14 & 3.774 & 0 & 13 \\
\hline
\end{tabular}

Abbreviations: FPI-R, Freiburger Personality Inventory - revised; SD, standard deviation.

and T2: $\left.F(1.48)=7.017, P=0.011, \eta_{2}=0.128\right)$. Patients with a lower degree of depression showed better hip functionality at every measurement (Figure 2).

\section{Anxiety and HHS}

The only significant effect of anxiety occurred 1 week after surgery and concerned trait anxiety $(\mathrm{T} 1: F(1.48)=9.900$, $P=0.003, \eta_{2}=0.171$; Figure 3 ).

\section{Resilience, personality traits, and HHS}

Resilience was not related to HHS outcome. After alphaadjusting the correlations between FPI-scores and HHS calculated for every point in time, the only significant correlation was between somatic pain and HHS at T1 $(r=-0.451$, $P=0.001)$.

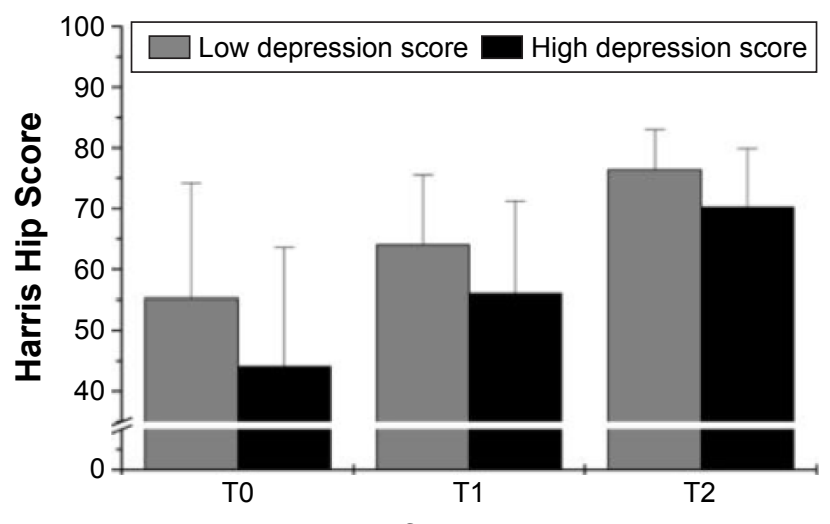

Time of measurement

Figure 2 Influence of depression on hip functionality (Harris Hip Score); the lower the depression score, the better hip functionality is.

Abbreviations: T0, prior to surgery; TI, I week after surgery; T2, 5 weeks after surgery. 


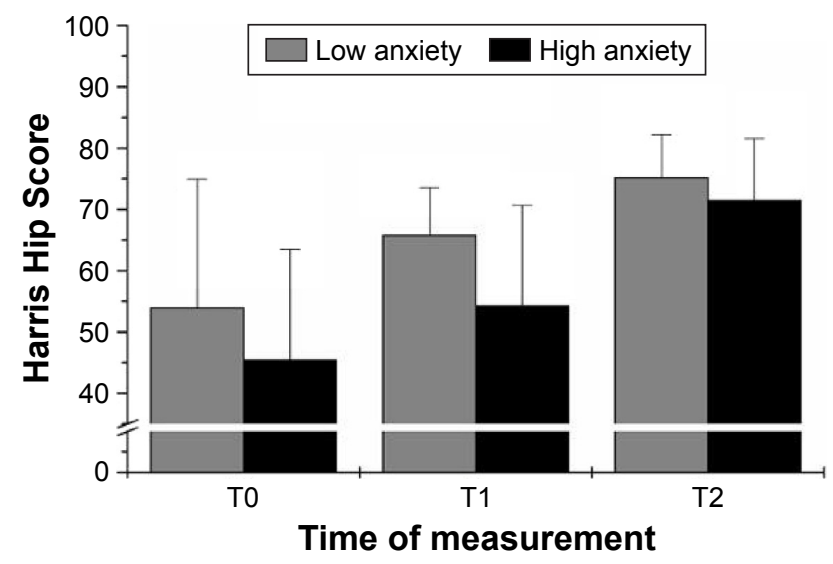

Figure 3 Influence of anxiety on hip functionality (measured by means of Harris Hip Score).

Abbreviations: T0, prior to surgery; TI, I week after surgery; T2, 5 weeks after surgery.

\section{Discussion}

The objective of our study was to examine various psychological variables potentially addressing outcome. The influence of psychological factors on outcome after surgery is undisputed. However, psychological factors are not routinely assessed before surgery. ${ }^{38}$ Furthermore, the most suitable yellow flag assessment tool for identifying psychological risk factors is still unclear. Establishing biopsychosocial models requires an understanding of what psychological factors mainly influence THA outcome.

Our study showed significant changes in depression and anxiety scores over the investigated period. Moreover, we found a significant relationship of depression and anxiety with hip functionality. The plausibility of our findings was shown by comparing our HHS results with those of another study, performed in our hospital earlier by Sendtner et al. ${ }^{39}$ The preoperative mean in Sendtner's study was 49.66 points, which was like our results. This score means that patients in both studies had "poor hip functionality". After 1 year, both HHS values in Sendtner's study rose to 92 points. Five weeks after surgery, our patients reached 73.28 points, which was a lower score than that of Sendtner's patients. However, this score seems comprehensible in view of the shorter postoperative period in our study.

\section{Primary outcome measure: depression as an influence factor}

Not only the psychological scores but also other experiments showed similar results. For instance, the ADS-L as a German version of the Center for Epidemiological Studies Depression Scale (CES-D) was used in a follow-up study on patients with fractures of the femoral neck. According to this study, 51\% of participants had elevated CES-D levels after surgery. The 1-year follow-up showed a correlation between high CES-D levels and poor hip functionality. ${ }^{16}$ Our investigation showed similar results. Initially, the mean rose from $16.80 \pm 8.75$ to $17.58 \pm 9.34$. Badura-Brzoza et $\mathrm{a}^{10}$ used a similar study design, measuring depression and its effects on THA outcome. They found higher preoperative depression levels that decreased after THA $(P=0.003)$. However, no effect on outcome could be shown. In contrast, Riediger et a ${ }^{13}$ showed a correlation between high depression levels and poor outcome. Depressive patients had a lower median WOMAC (Western Ontario McMaster Universities Osteoarthritis Index) sum score of 30 (versus 45) preoperatively and 72 (versus 85) postoperatively. Gold et a ${ }^{40}$ found depression to be associated with a significantly higher risk of readmission after THA. Our findings showed depression to be related to outcome at every measurement after THA, 1 week after surgery as well as after the 5 -week postoperative phase.

\section{Anxiety as an influence factor}

The STAI score was used to show the impact of anxiety on pain after THA and TKA. ${ }^{20}$ The study claimed state anxiety to be the only predictor for pain. Since pain is an important factor in the HHS (44 points in total), this comparison is very interesting. Our findings only showed an effect of trait anxiety 1 week after surgery. Montin et $\mathrm{al}^{9}$ explored the effect of anxiety after THA not in view of physical healing but in the context of psychological recovery with a focus on quality of life. ${ }^{8}$ STAI was also used in that investigation. Although no correlation was shown, their scientific research question was less interesting for our study than their concrete STAI results: the design of their experiment was similar to ours, with an initial preoperative value and follow-up measurements after 1 month. When preoperatively investigating 100 patients, Montin et $\mathrm{a}^{9}$ found a mean value of $44.5(\mathrm{SD}=4.5)$ at X1 and $42.8(\mathrm{SD}=4.9)$ at $\mathrm{X} 2$. At the same point of time, our patients had $44.06(\mathrm{SD}=12.3)$ at $\mathrm{X} 1$ and $38.7(\mathrm{SD}=9.9)$ at $\mathrm{X} 2$. One month after surgery, Montin et $\mathrm{al}^{9}$ measured 44.8 $(\mathrm{SD}=3.7)$ for state anxiety in contrast to $35.12(\mathrm{SD}=10.2)$ in our patients. Montin et $\mathrm{al}^{9}$ initially also measured trait anxiety only once. The comparison shows that their study design and methods were similar to our investigation, but also that we had almost identical preoperative values for state anxiety. From our point of view, it is surprising that the participants in Montin's study showed almost no change in state anxiety values. Even the values measured at the 6-month follow-up remained more or less the same, whereas our patients showed significantly improved values $(P \leq 0.001)$. 
From our perspective, this improvement corresponds with the situational character of state anxiety in a better way and seems therefore very plausible when taking the entire process into consideration. Badura-Brzoza et al ${ }^{10}$ also measured trait anxiety only once, yielding an arithmetic mean of 46.5 points. State anxiety was preoperatively calculated with 47.9 points and postoperatively with 41.1 points, which also supported our findings. Although the anxiety levels found by Badura-Brzoza et $\mathrm{al}^{10}$ were only slightly higher, the authors considered trait anxiety as the most important factor for quality of life. Despite the lack of exact matches between the cited studies and our results, there is a strong indication that changes in anxiety over the course of surgical treatment play an important role in outcome. Even though the cited studies focused on quality of life after surgery, our study showed similar results for hip functionality after THA.

\section{Resilience and personality traits as outcome predictors}

Besides depression and anxiety, we also measured patient resilience using the RS-11. Although several studies have focused on resilience, we could not find any study examining the influence of resilience on hip functionality after THA. ${ }^{41,42}$ Resilience did not change over the course of our study.

A comprehensive psychological view of our patients was obtained by using the FPI-R. The FPI-R is a long-term validated score that has been used in many different experiments on widely varying issues, even on orthopedics. ${ }^{43,44}$ One study showed that neuroticism is associated with mental $(P=0.03)$ and physical $(P=0.005)$ performance after THA. ${ }^{10}$ We could only find a significant correlation between somatic pain and HHS at 1 week after surgery.

In summary, our results confirmed that somatic variables are not the only ones responsible for pain and dysfunctionality after THA. Depression and trait anxiety seem to be the most important and reliable predictors for identifying psychological risk factors influencing outcome after THA. The results of this study may provide useful advice for supporting measures around the time of hip surgery in elderly people.

\section{Limitations}

Our study had some limitations. First, our study cohort was rather small because it included only patients staying at the clinic and the integrated rehabilitation center for 6 weeks. Although the follow-up period seems to be short, in choosing this period we wanted to minimize the risks of exogenous influence in the home environment. It remains unclear whether our results can be transferred to patients staying less than 6 weeks. Another limitation is that there is no blinding of researchers or participants, and as in all studies using scores, the truthfulness of patients' answers cannot be verified. The participants were included just one after the other by meeting the inclusion criteria, which can be a kind of selection bias.

\section{Conclusion}

Several studies have acknowledged the crucial role of psychological factors in the context of pain and disability associated with osteoarthritis. Only a few publications have considered psychological factors when examining outcome after joint replacement surgery. Our findings show that THA is a very stressful situation for patients with enormous changes in depression and anxiety levels. Every fifth patient had critical depression values, and more than two-thirds of our study participants had abnormal anxiety levels. Our results showed a significant negative relationship, particularly of high-level depression on hip functionality after THA. Of course, this study represents only one method of investigating the effects of psychological factors on outcome after THA. Vissers et $\mathrm{al}^{7}$ claimed that relatively few studies evaluated the effects of psychological factors on outcome after THA. Our study gives the first comprehensive picture of different psychological factors relating to the short-term outcome after hip surgery. The results of the present study emphasize the important role of psychological factors on outcome after surgery. Screening procedures could identify high-risk patients and ensure an integrated therapy. Therefore, further studies are required to develop a more evidence-based therapeutic procedure, to investigate the effect of depression on long-term outcome, and to investigate whether preoperative treatment of depression may improve outcome after THA.

\section{Acknowledgment}

The authors thank Monika Schöll for the linguistic review of their manuscript. This work was supported by the German Research Foundation (DFG) within the funding program, Open Access Publishing.

\section{Disclosure}

The authors report no conflicts of interest in this work.

\section{References}

1. Kim C, Linsenmeyer KD, Vlad SC, et al. Prevalence of radiographic and symptomatic hip osteoarthritis in an urban United States community: the Framingham osteoarthritis study. Arthritis Rheumatol. 2014;66(11):3013-3017. 
2. Jonsson H, Olafsdottir S, Sigurdardottir S, et al. Incidence and prevalence of total joint replacements due to osteoarthritis in the elderly: risk factors and factors associated with late life prevalence in the AGESReykjavik Study. BMC Musculoskelet Disord. 2016;17:14.

3. Kay A, Davison B, Badley E, Wagstaff S. Hip arthroplasty: patient satisfaction. Br J Rheumatol. 1983;22:243-249.

4. Shan L, Shan B, Graham D, Saxena A. Total hip replacement: a systematic review and meta-analysis on mid-term quality of life. Osteoarthritis Cartilage. 2014;22:389-406.

5. Mancuso CA, Salvati EA. Patients' satisfaction with the process of total hip arthroplasty. J Healthc Qual. 2003;25: 12-18; quiz 18-19.

6. Anakwe RE, Jenkins PJ, Moran M. Predicting dissatisfaction after total hip arthroplasty: a study of 850 patients. $J$ Arthroplasty. 2011;26: 209-213.

7. Vissers MM, Bussmann JB, Verhaar JA, et al. Psychological factors affecting the outcome of total hip and knee arthroplasty: a systematic review. Semin Arthritis Rheum. 2012;41:576-588.

8. Salmon P, Hall GM, Peerbhoy D. Influence of the emotional response to surgery on functional recovery during 6 months after hip arthroplasty. J Behav Med. 2001;24:489-502.

9. Montin L, Leino-Kilpi H, Katajisto J, Lepistö J, Kettunen J, Suominen T. Anxiety and health-related quality of life of patients undergoing total hip arthroplasty for osteoarthritis. Chronic Illn 2007;3:219-227.

10. Badura-Brzoza K, Zajac P, Brzoza Z, et al. Psychological and psychiatric factors related to health-related quality of life after total hip replacement - preliminary report. Eur Psychiatry. 2009;24:119-124.

11. Badura-Brzoza K, Zajac P, Kasperska-Zajac A, et al. Anxiety and depression and their influence on the quality of life after total hip replacement: preliminary report. Int J Psychiatry Clin Pract. 2008;12:280-284.

12. Quintana JM, Escobar A, Aguirre U, Lafuente I, Arenaza JC. Predictors of health-related quality-of-life change after total hip arthroplasty. Clin Orthop Relat Res. 2009;467:2886-2894.

13. Riediger W, Doering S, Krismer M. Depression and somatisation influence the outcome of total hip replacement. Int Orthop. 2010;34: $13-18$.

14. Whiteford HA, Ferrari AJ, Degenhardt L, Feigin V, Vos T. The global burden of mental, neurological and substance use disorders: an analysis from the Global Burden of Disease Study 2010. PLoS One. 2015 10:e0116820.

15. Moussavi S, Chatterji S, Verdes E, Tandon A, Patel V, Ustun B. Depression, chronic diseases, and decrements in health: results from the World Health Surveys. Lancet. 2007;370:851-858.

16. Mossey JM, Knott K, Craik R. The effects of persistent depressive symptoms on hip fracture recovery. J Gerontol. 1990;45:M163-M168.

17. Fortinsky RH, Bohannon RW, Litt MD, et al. Rehabilitation therapy self-efficacy and functional recovery after hip fracture. Int $J$ Rehabil Res. 2002;25:241-246.

18. Gong HS, Lee JO, Huh JK, Oh JH, Kim SH, Baek GH. Comparison of depressive symptoms during the early recovery period in patients with a distal radius fracture treated by volar plating and cast immobilisation. Injury. 2011;42:1266-1270.

19. Tristaino V, Lantieri F, Tornago S, Gramazio M, Carriere E, Camera A Effectiveness of psychological support in patients undergoing primary total hip or knee arthroplasty: a controlled cohort study. J Orthop Traumatol. 2016;17:137-147.

20. Feeney SL. The relationship between pain and negative affect in older adults: anxiety as a predictor of pain. J Anxiety Disord. 2004; 18:733-744.

21. Rasouli MR, Menendez ME, Sayadipour A, Purtill JJ, Parvizi J. Direct cost and complications associated with total joint arthroplasty in patients with preoperative anxiety and depression. J Arthroplasty. 2016;31:533-536.

22. Buller LT, Best MJ, Klika AK, Barsoum WK. The influence of psychiatric comorbidity on perioperative outcomes following primary total hip and knee arthroplasty; a 17-year analysis of the National Hospital Discharge Survey database. J Arthroplasty. 2015;30:165-170.
23. Meyer TD, Hautzinger M. Prediction of personality disorder traits by psychosis proneness scales in a German sample of young adults. J Clin Psychol. 2002;58:1091-1101.

24. Hammer EM, Häcker S, Hautzinger M, Meyer TD, Kübler A. Validity of the ALS-Depression-Inventory (ADI-12) - a new screening instrument for depressive disorders in patients with amyotrophic lateral sclerosis. J Affect Disord. 2008;109:213-219.

25. Reime B, Steiner I. [Burned-out or depressive? An empirical study regarding the construct validity of burnout in contrast to depression]. Psychother Psychosom Med Psychol. 2001;51:304-307.

26. Meyer TD, Hautzinger M. Allgemeine Depressions-Skala (ADS). Diagnostica. 2001;47:208-215.

27. Pauls CA, Stemmler G. Repressive and defensive coping during fear and anger. Emotion. 2003;3:284-302.

28. Spielberger CD. State-Trait Anxiety Inventory: Bibliography. 2nd ed. Palo Alto, CA: Consulting Psychologists Press; 1989.

29. Wagnild GM, Young HM. Development and psychometric evaluation of the Resilience Scale. J Nurs Meas. 1993;1:165-178.

30. Luthar SS, Cicchetti D, Becker B. The construct of resilience: a critical evaluation and guidelines for future work. Child Dev. 2000;71:543-562.

31. Fahrenberg J, Hampel R, Selg H. Freiburger Persönlichkeitsinventar (FPI-R). erweiterte Auflage. Manual. Goettingen, Germany: Hogrefe; 2010.

32. Harris WH. Traumatic arthritis of the hip after dislocation and acetabular fractures: treatment by mold arthroplasty. An end-result study using a new method of result evaluation. J Bone Joint Surg Am. 1969;51(4): $737-755$.

33. Singh JA, Schleck C, Harmsen S, Lewallen D. Clinically important improvement thresholds for Harris Hip Score and its ability to predict revision risk after primary total hip arthroplasty. BMC Musculoskelet Disord. 2016;17:256.

34. Söderman P, Malchau H, Herberts P. Outcome of total hip replacement: a comparison of different measurement methods. Clin Orthop Relat Res. 2001;(390):163-172.

35. Söderman P, Malchau H. Is the Harris hip score system useful to study the outcome of total hip replacement? Clin Orthop Relat Res. 2001;(384):189-197.

36. Kavanagh BF, Fitzgerald RH Jr. Clinical and roentgenographic assessment of total hip arthroplasty. A new hip score. Clin Orthop Relat Res. 1985;(193):133-140.

37. Wright JG, Young NL. A comparison of different indices of responsiveness. J Clin Epidemiol. 1997;50:239-246.

38. Lentz TA, Beneciuk JM, Bialosky JE, et al. Development of a yellow flag assessment tool for orthopaedic physical therapists: results from the Optimal Screening for Prediction of Referral and Outcome (OSPRO) Cohort. J Orthop Sports Phys Ther. 2016;46:327-343.

39. Sendtner E, Borowiak K, Schuster T, Woerner M, Grifka J, Renkawitz T. Tackling the learning curve: comparison between the anterior, minimally invasive (Micro-hip ${ }^{\circledR}$ ) and the lateral, transgluteal (Bauer) approach for primary total hip replacement. Arch Orthop Trauma Surg. 2011;131:597-602.

40. Gold HT, Slover JD, Joo L, Bosco J, Iorio R, Oh C. Association of depression with 90-day hospital readmission after total joint arthroplasty. J Arthroplasty. 2016;31:2385-2388.

41. Catalano D, Chan F, Wilson L, Chiu CY, Muller VR. The buffering effect of resilience on depression among individuals with spinal cord injury: a structural equation model. Rehabil Psychol. 2011;56:200-211.

42. Ramírez-Maestre C, Esteve R, López AE. The path to capacity: resilience and spinal chronic pain. Spine (Phila Pa 1976). 2012;37:E251-E258.

43. Radl R, Leithner A, Zacherl M, Lackner U, Egger J, Windhager R. The influence of personality traits on the subjective outcome of operative hallux valgus correction. Int Orthop. 2004;28:303-306.

44. Härtl K, Engel J, Herschbach P, Reinecker H, Sommer H, Friese K. Personality traits and psychosocial stress: quality of life over 2 years following breast cancer diagnosis and psychological impact factors. Psychooncology. 2010;19:160-169. 


\section{Publish your work in this journal}

Therapeutics and Clinical Risk Management is an international, peerreviewed journal of clinical therapeutics and risk management, focusing on concise rapid reporting of clinical studies in all therapeutic areas, outcomes, safety, and programs for the effective, safe, and sustained use of medicines. This journal is indexed on PubMed Central, CAS,

EMBase, Scopus and the Elsevier Bibliographic databases. The manuscript management system is completely online and includes a very quick and fair peer-review system, which is all easy to use. Visit http://www.dovepress.com/testimonials.php to read real quotes from published authors.

Submit your manuscript here: http://www.dovepress.com/therapeutics-and-clinical-risk-management-journal 